\title{
Dual-Biomarker Imaging of Regional Cerebral Amyloid Load and Neuronal Activity in Dementia with PET and ${ }^{11}$ C-Labeled Pittsburgh Compound B
}

\author{
Philipp T. Meyer ${ }^{1}$, Sabine Hellwig ${ }^{2}$, Florian Amtage ${ }^{3}$, Christof Rottenburger ${ }^{1}$, Ursula Sahm ${ }^{1}$, Peter Reuland ${ }^{1}$, \\ Wolfgang A. Weber ${ }^{1}$, and Michael Hüll ${ }^{4}$ \\ ${ }^{1}$ Department of Nuclear Medicine, University Hospital Freiburg, Freiburg, Germany; ${ }^{2}$ Department of Psychiatry and Psychotherapy, \\ University Hospital Freiburg, Freiburg, Germany; ${ }^{3}$ Department of Neurology, University Hospital Freiburg, Freiburg, Germany; and \\ ${ }^{4}$ Centre for Geriatric Medicine and Gerontology, University Hospital Freiburg, Freiburg, Germany
}

PET studies with biomarkers of regional neuronal activity (cerebral glucose metabolism or blood flow [CBF]) and amyloid- $\beta(A \beta)$ depositions provide complementary information for the early diagnosis of dementia and follow-up of patients with dementia. We investigated the validity of relative regional CBF estimates $\left(R_{1}\right)$ gained from pharmacokinetic analyses of ${ }^{11} \mathrm{C}$ labeled Pittsburgh compound B $\left({ }^{11} \mathrm{C}-\mathrm{PIB}\right)$ PET studies as a marker of neuronal activity and neurodegeneration. Methods: Twenty-two patients with cognitive impairment (16 patients with early Alzheimer disease) underwent ${ }^{18} \mathrm{~F}-\mathrm{FDG}$ and ${ }^{11} \mathrm{C}-\mathrm{PIB}$ PET studies for the assessment of regional glucose metabolism and $\mathrm{A} \beta$ load. Parametric images of $R_{1}$ (relative CBF) and binding potential $\left(B P_{\mathrm{ND}} ; A \beta\right.$ load) were generated by 2-step simplified reference tissue model (SRTM2) analyses of dynamic ${ }^{11} \mathrm{C}-\mathrm{PIB}$ data. Volume-of-interest and voxel-based statistical analyses were performed to investigate the association between normalized ${ }^{18} \mathrm{~F}-\mathrm{FDG}$ uptake and ${ }^{11} \mathrm{C}-\mathrm{PIB} R_{1}$ and the correlation of these measures with symptom severity (Mini-Mental State Examination [MMSE] scores) in patients with Alzheimer disease. Results: SRTM2 analyses provided high-quality ${ }^{11} \mathrm{C}-\mathrm{PIB} R_{1}$ images that were comparable to ${ }^{18} \mathrm{~F}-\mathrm{FDG}$ PET images. Regional ${ }^{11} \mathrm{C}-\mathrm{PIB} R_{1}$ values strongly correlated with normalized regional ${ }^{18} \mathrm{~F}-\mathrm{FDG}$ uptake when correlations were calculated separately for each patient $\left(R^{2}\right.$ [mean $\pm \mathrm{SD}$ ], $\left.0.73 \pm 0.11\right)$ or across all regions of all patients $\left(R^{2}, 0.62\right)$. A regression model including ${ }^{18} \mathrm{~F}-\mathrm{FDG}$ uptake, subject identification, and region grouping (into cortical, subcortical, and limbic regions to allow for possible differences in flow/metabolism coupling) accounted for $86 \%$ of total ${ }^{11} \mathrm{C}-\mathrm{PIB} R_{1}$ variability. Voxel-based correlation analyses of ${ }^{18} \mathrm{~F}-\mathrm{FDG}$ uptake and ${ }^{11} \mathrm{C}-\mathrm{PIB} R_{1}$ with MMSE scores revealed similar core findings of positive correlations in the posterior cingulate gyrus/precuneus and negative correlations (preserved activity) in the bilateral sensorimotor cortex. There was no correlation between $A \beta$ load $\left(B P_{\mathrm{ND}}\right)$ and MMSE scores. Conclusion: These results strongly suggest that ${ }^{11} \mathrm{C}$-PIB $R_{1}$ can serve as a complementary biomarker of neuronal activity and, thus, neurodegeneration in addition to $A \beta$ load given by ${ }^{11} \mathrm{C}$-PIB $B P_{\mathrm{ND}}$. Further studies are needed to validate

Received Sep. 28, 2010; revision accepted Dec. 1, 2010.

For correspondence contact: Philipp T. Meyer, Department of Nuclear Medicine, University Hospital Freiburg, Hugstetter Strasse 55, 79110 Freiburg, Germany.

E-mail: philipp.meyer@uniklinik-freiburg.de

COPYRIGHT @ 2011 by the Society of Nuclear Medicine, Inc. the diagnostic value of dual-biomarker ${ }^{11} \mathrm{C}$-PIB PET studies in comparison with combined ${ }^{18} \mathrm{~F}-\mathrm{FDG}$ and ${ }^{11} \mathrm{C}$-PIB PET studies. Compared with the latter, dual-biomarker ${ }^{11} \mathrm{C}$-PIB PET greatly reduces costs and burden for patients.

Key Words: PET; ${ }^{11} \mathrm{C}-\mathrm{PIB}$; pharmacokinetic modeling; Alzheimer disease

J Nucl Med 2011; 52:393-400

DOI: 10.2967/jnumed.110.083683

$\mathbf{N}$

umerous molecular targets and functional processes imaged with PET and SPECT have been proposed as biomarkers for the investigation of neurodegenerative dementia, in particular, Alzheimer disease (AD) (1). Regional cerebral glucose metabolism (measured by PET with ${ }^{18} \mathrm{~F}-\mathrm{FDG}$ ) and regional cerebral blood flow (CBF) have been extensively used as biomarkers of synaptic dysfunction and neurodegeneration. Under physiologic conditions (at rest and during activation), they are closely coupled markers of neuronal activity (2). Furthermore, a comparison of both biomarkers in $\mathrm{AD}$ suggests that $\mathrm{AD}$-induced changes in $\mathrm{CBF}$ and glucose metabolism are also tightly coupled (3). Another biomarker of $\mathrm{AD}$, which has gained tremendous attention and acceptance in recent years, is cerebral amyloid- $\beta(A \beta)$ peptide deposition imaged with PET. Several A $\beta$ tracers have been reported (1); the most notable is ${ }^{11} \mathrm{C}$-labeled Pittsburgh compound B ( $\left.{ }^{11} \mathrm{C}-\mathrm{PIB}\right)(4)$. Together with neurofibrillary tangles formed by protein tau, cerebral $A \beta$ aggregates represent the histopathologic hallmark of $\mathrm{AD}$ ( $\mathrm{A} \beta$ plaques) and play a pivotal role in its early pathogenesis (5).

Because of differences in the nature and temporal order of the aforementioned biomarkers (i.e., early marker of $\mathrm{AD}$ vs. downstream synaptic dysfunction and neurodegeneration) (5), these biomarkers provide highly complementary information. For instance, positive results of ${ }^{11} \mathrm{C}$-PIB scans are found not only in $\mathrm{AD}$ dementia $(4,6,7)$ but also in diseases with concomitant $\mathrm{AD}$ pathology, most notably, dementia with Lewy bodies $(6,8)$. In addition, for a significant fraction of cognitively healthy elderly people (up to $30 \%$ ), ${ }^{11} \mathrm{C}$-PIB 
scan results are positive $(4,6,9)$. Conversely, negative results of ${ }^{11} \mathrm{C}$-PIB scans are expected in frontotemporal lobar degeneration $(6)$, the majority of patients with Parkinson disease with dementia (8), and cognitive impairment with many other causes. Thus, an additional ${ }^{18} \mathrm{~F}-\mathrm{FDG}$ or $\mathrm{CBF}$ study can be helpful in establishing the correct diagnosis by depicting disease-specific patterns of neurodegeneration.

Furthermore, an increasing body of evidence suggests that cerebral $A \beta$ amyloidosis starts $10-15 \mathrm{y}$ before the first cognitive symptoms and, therefore, that the aforementioned ${ }^{11} \mathrm{C}$-PIB-positive healthy subjects have preclinical $\operatorname{AD}(5,10,11)$. In line with this notion, ${ }^{11} \mathrm{C}$-PIB PET had a predictive value for cognitive decline and conversion to $\mathrm{AD}$ dementia in healthy volunteers and patients with mild cognitive impairment (MCI) $(11,12)$. However, ${ }^{11} \mathrm{C}$-PIB PET was found to be rather insensitive for assessing $\mathrm{AD}$ progression and dementia severity, possibly because the rate of $A \beta$ accumulation reached a plateau in symptomatic AD stages $(5,13,14)$, although the findings are controversial (15). In contrast, measures of neurodegeneration, such as ${ }^{18}$ F-FDG PET, showed a strong correlation with dementia severity and $\mathrm{AD}$ progression $(13,14,16,17)$. Thus, although ${ }^{11} \mathrm{C}$-PIB PET is a powerful tool for the (early) diagnosis of AD pathology, an additional ${ }^{18} \mathrm{~F}$-FDG or CBF study is valuable for determining the degree and progression of neurodegeneration. The latter is particularly true for patient selection and treatment monitoring in antiamyloid treatment studies of AD $(1,15,18)$.

Combining different PET biomarkers in dual-tracer studies results in increased costs, discomfort for patients, and radiation exposure. However, as demonstrated for other ligands $(19,20)$, pharmacokinetic analyses of ${ }^{11} \mathrm{C}$-PIB studies may yield diagnostically valuable estimates of relative regional CBF: Invasive compartment models used for ${ }^{11} \mathrm{C}$ PIB quantification $(21,22)$ provided estimates of $K_{1}$ (i.e., the rate constant for ligand transfer from arterial plasma to tissue). In radiotracers with a high permeability-surface product and, consequently, a high level of first-pass extraction, $K_{1}$ is closely related to $\mathrm{CBF}$. As a prerequisite for the use of ${ }^{11} \mathrm{C}$ PIB for CBF estimation, combined ${ }^{15} \mathrm{O}$-water and ${ }^{11} \mathrm{C}$-PIB PET studies in rhesus monkeys demonstrated a high level of ${ }^{11} \mathrm{C}$-PIB first-pass extraction $(77 \% \pm 8 \%$ [mean $\left.\pm \mathrm{SD}]\right)(21)$. Moreover, regional $\mathrm{CBF}$ changes were paralleled by comparable ${ }^{11} \mathrm{C}$-PIB $K_{1}$ changes in the monkeys $(21)$. Thus, ${ }^{11} \mathrm{C}$ PIB $K_{1}$ can be expected to provide a reasonable estimate of relative regional $\mathrm{CBF}$.

Several noninvasive kinetic analyses (with the cerebellum as a reference region) have been validated for ${ }^{11} \mathrm{C}$-PIB studies in humans (23-25). Of these, the 2-step simplified reference tissue model (SRTM2) (26) is particularly attractive for fast and easy computation of high-quality parametric images of $\mathrm{A} \beta$ plaque binding and relative tracer delivery $\left(R_{1}\right)$ (25). Because $R_{1}$ is equal to the ratio of the $K_{1}$ of the target region to the $K_{1}$ of the reference region, it also represents a measure of relative regional $\mathrm{CBF}$.
The aim of the present study was to explore the use of ${ }^{11} \mathrm{C}$-PIB $R_{1}$ as a marker of regional neuronal activity and neurodegeneration in dementia. To this end, we compared regional ${ }^{11} \mathrm{C}$-PIB $R_{1}$ estimates gained from voxelwise SRTM2 analyses with estimates of relative regional glucose metabolism obtained from ${ }^{18} \mathrm{~F}-\mathrm{FDG}$ PET in the same patients. In addition, we performed voxelwise correlation analyses using ${ }^{11} \mathrm{C}$-PIB $R_{1}$ and dementia severity and compared the results with those of correlation analyses using ${ }^{18} \mathrm{~F}-\mathrm{FDG}$.

\section{MATERIALS AND METHODS \\ Patients}

PET data from 22 consecutive patients (13 men and 9 women; age, $67.9 \pm 8.1$ y) who underwent combined ${ }^{11} \mathrm{C}$-PIB and ${ }^{18} \mathrm{~F}-\mathrm{FDG}$ PET examinations were analyzed after the patients gave written informed consent, as approved by the local ethics commission. We intentionally investigated a sample of consecutive patients with different causes of cognitive impairment because such a sample should be most representative of the clinical situation. Fifteen patients fulfilled the criteria for probable $\mathrm{AD}$, according to the criteria of the National Institute of Neurologic and Communicative Disorders and Stroke and the Alzheimer Disease and Related Disorders Association (27). The average Mini-Mental State Examination (MMSE) score in these patients was $22.7 \pm 3.7$ ( 1 patient had a score of 10; all others had scores of 22-25). For the other 7 patients, the most likely diagnoses, according to consensus criteria, were frontotemporal lobar degeneration in 3 patients (MMSE scores of 24, 26, and 27) (28) and MCI in 3 patients (MMSE scores of 25, 27, and 28) (29); the most likely cause of cognitive impairment in the remaining patient was depression (MMSE score of 27).

\section{PET Acquisition}

All patients underwent ${ }^{11} \mathrm{C}$-PIB PET and ${ }^{18} \mathrm{~F}-\mathrm{FDG}$ PET examinations with the same PET system (ECAT EXACT 922/47; Siemens-CTI). Both scans were acquired on the same day in 11 patients $\left({ }^{18} \mathrm{~F}\right.$-FDG PET about $2 \mathrm{~h}$ after ${ }^{11} \mathrm{C}$-PIB injection; 1-h break between examinations) or within $1 \mathrm{wk}$ in 9 patients. In 1 patient each, the delays were 1 and 6 mo.

Both scans were performed under resting conditions with the eyes open, ambient noise, and dimmed light. For each acquisition, the patient's head was gently restrained with an elastic tape; the position of the head was carefully monitored and, if necessary, manually corrected throughout the data acquisition with the guidance of the scanner laser beams and reference skin marks. Movements were usually small (i.e., below the scanner resolution) and corrected immediately. Thus, no additional software-based motion correction was performed.

${ }^{11} \mathrm{C}$-PIB radiochemical synthesis was performed as previously described (30) (the precursor was provided by $\mathrm{ABX} \mathrm{GmbH}$ ). The radiochemical purity was greater than $95 \%$, and the specific activity at the time of injection was greater than $74 \mathrm{GBq} / \mu \mathrm{mol}$ in each patient. After a 5 -min ${ }^{68} \mathrm{Ge} /{ }^{68} \mathrm{Ga}$ transmission scan for attenuation correction, a dynamic ${ }^{11} \mathrm{C}$-PIB PET acquisition lasting $60 \mathrm{~min}$ (frames: $3 \times 20 \mathrm{~s}, 3 \times 30 \mathrm{~s}, 2 \times 60 \mathrm{~s}, 2 \times 90 \mathrm{~s}, 3 \times 150 \mathrm{~s}$, and $9 \times 300 \mathrm{~s}$ ) was started with an intravenous bolus injection of $451 \pm$ $104 \mathrm{MBq}$ of ${ }^{11} \mathrm{C}$-PIB.

${ }^{18} \mathrm{~F}$-FDG PET scans were obtained $40 \mathrm{~min}$ after an intravenous injection of $303 \pm 10 \mathrm{MBq}$ of ${ }^{18}$ F-FDG. All patients fasted for at least $6 \mathrm{~h}$ before tracer injection; plasma glucose levels were within 
the reference range. Four 5-min frames were collected in the 2-dimensional mode with subsequent calculated attenuation correction. Summed PET datasets (total scan time of $20 \mathrm{~min}$ ) were used for further data analyses.

\section{Data Analyses}

Data analyses were done with the PMOD software package (version 3.0; PMOD Technologies Ltd.) as follows.

Parametric images of regional $\mathrm{A} \beta$ load (i.e., $B P_{\mathrm{ND}}$ images) and relative CBF (i.e., $R_{1}$ images) were generated with the SRTM2 (26). This model takes advantage of the fact that $k_{2}{ }^{\prime}$ (i.e., the efflux rate constant for ${ }^{11} \mathrm{C}$-PIB from the reference region) can be fixed to a single, patient-specific value for all regional analyses. Thus, only 2 free model parameters $\left(B P_{\mathrm{ND}}\right.$ and $\left.R_{1}\right)$ are left, greatly facilitating voxelwise analyses. The cerebellum was chosen as the reference region (without relevant specific ${ }^{11} \mathrm{C}$-PIB binding) (4).

To apply this model, we estimated $k_{2}{ }^{\prime}$ for each patient by using the 3-parameter $\left(B P_{\mathrm{ND}}, R_{1}\right.$, and $\left.k_{2}^{\prime}\right)$ simplified reference tissue model (SRTM) (31) and regional time-activity curves. Decaycorrected regional time-activity curves were assessed in a highly standardized fashion by applying a volume-of-interest (VOI) template to the individual dynamic ${ }^{11} \mathrm{C}$-PIB frames after they were spatially normalized to the Montreal Neurologic Institute (MNI) space. The latter process involved spatial normalization of the individual ${ }^{11} \mathrm{C}$-PIB integral image of the first $6 \mathrm{~min}$ (CBF-like distribution; see "Discussion") to the MNI ${ }^{18}$ F-FDG template image provided by PMOD (mutual information algorithm). Normalization parameters were then applied to the individual PET frames. The VOI template was defined on the corresponding MNI MRI template and comprised 14 pairs of bilateral VOIs (frontal cortex, orbitofrontal cortex, parietal cortex, temporal cortex, mesiotemporal lobe, occipital cortex, sensorimotor cortex, anterior cingulate gyrus, posterior cingulate gyrus/precuneus, insula, caudate nucleus, putamen, thalamus, and cerebellar cortex) and a VOI for the pons. After fitting of the SRTM to the frontal cortex time-activity curve (initial settings according to Yaqub et al. (25)), the resulting estimated parameters were used as initial parameters for regional SRTM fitting. Subsequently, the average $k_{2}{ }^{\prime}$ estimate across all target regions was calculated for each patient and used as a fixed parameter in voxelwise SRTM2 analyses of the original, nonnormalized ${ }^{11} \mathrm{C}$-PIB data. For direct comparisons, ${ }^{18} \mathrm{~F}$-FDG and ${ }^{11} \mathrm{C}$-PIB $R_{1}$ datasets were spatially normalized to the MNI ${ }^{18} \mathrm{~F}$-FDG template. Normalization parameters for the ${ }^{11} \mathrm{C}$-PIB $R_{1}$ dataset were also applied to the ${ }^{11} \mathrm{C}$-PIB $B P_{\mathrm{ND}}$ dataset. All normalized datasets were analyzed by use of the aforementioned VOI template to assess side-averaged mean regional ${ }^{18} \mathrm{~F}-\mathrm{FDG}$ uptake and $R_{1}$ and $B P_{\mathrm{ND}}$ values. Finally, regional ${ }^{18} \mathrm{~F}$-FDG uptake values were normalized to the ${ }^{18} \mathrm{~F}$ FDG uptake in the cerebellum (by analogy to the definition of $R_{1}$ ).

\section{Statistics}

A general linear model was used to explore the association between regional $R_{1}$ estimates (continuous dependent variable) and normalized regional ${ }^{18} \mathrm{~F}-\mathrm{FDG}$ uptake (continuous independent variable). Through flow/metabolism coupling, regional cerebral glucose metabolism ( ${ }^{18} \mathrm{~F}$-FDG uptake) was expected to be the major determinant of $\mathrm{CBF}$ and, thus, $R_{1}$. In addition, 2 categoric variables were explored as contributing variables. First, Gur et al. (32) demonstrated that flow/metabolism coupling is not homogeneous across regions (i.e., relative hyperperfusion of subcortical and limbic regions and relative hypoperfusion of association cor- tices). Thus, we grouped our VOIs, by analogy to Gur et al. (32), into subcortical (caudate nucleus, putamen, thalamus, and pons), limbic (orbitofrontal cortex, mesiotemporal lobe, anterior cingulate gyrus, posterior cingulate gyrus/precuneus, and insula), and cortical (frontal cortex, parietal cortex, sensorimotor cortex, temporal cortex, and occipital cortex) regions. Second, because flow/metabolism coupling cannot be assumed to be homogeneous across subjects, subject identification was also included. Linear regression analyses were performed to assess the association between regional ${ }^{11} \mathrm{C}$-PIB $R_{1}$ estimates and normalized ${ }^{18} \mathrm{~F}-\mathrm{FDG}$ uptake values. These statistical analyses were done with JMP 8 (SAS Institute Inc.).

To explore the association between symptom severity (measured with MMSE scores) and ${ }^{18}$ F-FDG uptake, ${ }^{11} \mathrm{C}$-PIB $R_{1}$, and ${ }^{11} \mathrm{C}$-PIB $B P_{\mathrm{ND}}$, we performed voxelwise statistical analyses with statistical parametric mapping (SPM) (SPM2; Wellcome Trust Centre for Neuroimaging). We included all patients with probable $\mathrm{AD}$ (except for the patient with the notably lower MMSE score of 10) and 2 patients with MCI and positive ${ }^{11} \mathrm{C}$-PIB scan results (strongly suggesting an $\mathrm{AD}$ prodromal stage). Thus, 16 patients with MMSE scores of 22-28 were included. After smoothing of ${ }^{18} \mathrm{~F}-\mathrm{FDG}$ uptake, $R_{1}$, and $B P_{\mathrm{ND}}$ datasets with a $10-\mathrm{mm}$ gaussian filter, voxelwise correlations were calculated. ${ }^{18} \mathrm{~F}-\mathrm{FDG}$ and $R_{1}$ datasets were processed with proportional scaling to account for global metabolism and perfusion effects in a uniform way. $B P_{\mathrm{ND}}$ maps (absolute measure) were processed without proportional scaling. Thresholds were applied to SPM $t$-maps for positive and negative correlations by use of a voxel height threshold of $2.98(P<0.005$; uncorrected $)$ and an extent threshold $\left(k_{\mathrm{E}}\right)$ of greater than 100 voxels. We intentionally used these rather liberal statistical thresholds because our primary aim was to compare correlation findings (mostly known) among methods, not to establish correlation patterns.

\section{RESULTS}

\section{General Results}

Thirteen of 15 patients with probable $\mathrm{AD}$ and 2 of 3 patients with $\mathrm{MCI}$ showed increased cortical ${ }^{11} \mathrm{C}$-PIB binding; the remaining 7 patients ( 5 with frontotemporal lobar degeneration, 1 with MCI, and 1 with depression) did not. The volume-weighted regional $B P_{\mathrm{ND}}$ values (mean $\pm \mathrm{SD}$ ) were $0.19 \pm 0.13$ (range, 0.06-0.45) and $1.16 \pm 0.29$ (0.62-1.64) in the ${ }^{11} \mathrm{C}$-PIB-negative and ${ }^{11} \mathrm{C}$-PIB-positive patients, respectively (including the frontal cortex, orbitofrontal cortex, posterior cingulate gyrus/precuneus, parietal cortex, and temporal cortex). Of note, the two ${ }^{11} \mathrm{C}-\mathrm{PIB}-$ negative patients and a clinical diagnosis of $\mathrm{AD}$ showed a glucose metabolism pattern compatible with or typical of AD.

The estimated average $k_{2}{ }^{\prime}$ value was $0.056 \pm 0.011 \mathrm{~min}^{-1}$. There was no significant difference in $k_{2}{ }^{\prime}$ values between ${ }^{11} \mathrm{C}$-PIB-positive patients $\left(0.058 \pm 0.012 \mathrm{~min}^{-1}\right)$ and ${ }^{11} \mathrm{C}$ PIB-negative patients $\left(0.052 \pm 0.006 \mathrm{~min}^{-1}\right)(P=0.3$; unpaired $t$ test).

\section{Comparison of Parametric ${ }^{11} \mathrm{C}-\mathrm{PIB} \boldsymbol{R}_{1}$ Images and 18F-FDG Uptake Images}

Figures 1-3 and Supplemental Figure 1 (supplemental materials are available online only at http://jnm.snmjournals. 


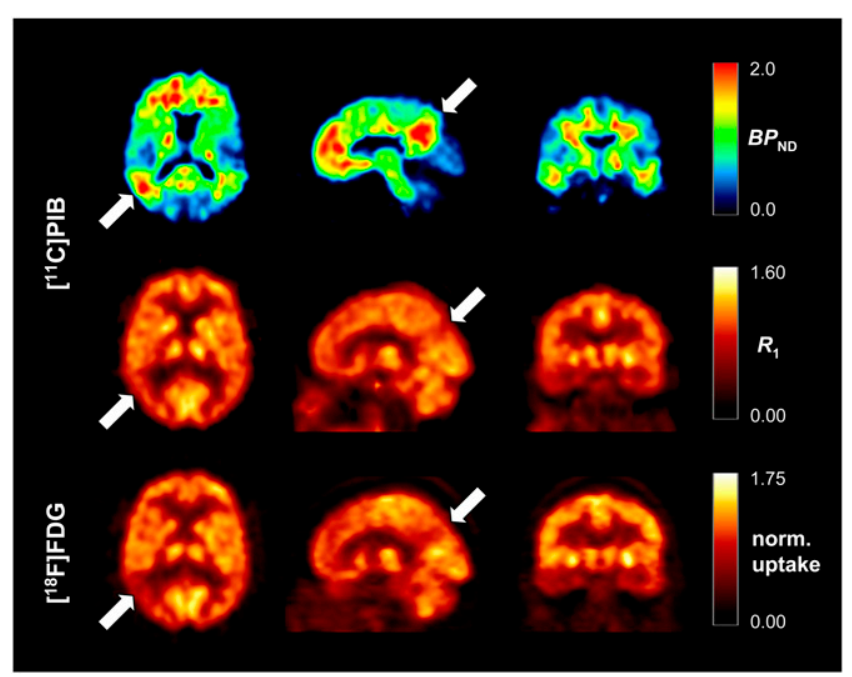

FIGURE 1. Parametric images of ${ }^{11} \mathrm{C}-\mathrm{PIB}$ binding potential $\left(B P_{\mathrm{ND}}\right.$; first row) and relative CBF ( $R_{1}$; second row) and normalized (norm.) ${ }^{18} \mathrm{~F}-\mathrm{FDG}$ uptake (third row) in patient with early Alzheimer disease (AD; MMSE score, 25). Marked A $\beta$ depositions are found in bilateral (right greater than left) frontal, temporoparietal, and posterior cingulate gyrus/precuneus cortex (first row), with concomitant reductions in relative regional blood flow and glucose metabolism in latter 2 areas on right side (arrows). Shown are corresponding transaxial, sagittal, and coronal slices. Note that color scales of ${ }^{11} \mathrm{C}$-PIB $R_{1}$ and normalized ${ }^{18} \mathrm{~F}$-FDG uptake images were individually adjusted for optimal illustration. See color scale maximum for quantitative comparison.

org) depict representative studies. Shown are parametric images of ${ }^{11} \mathrm{C}$-PIB $B P_{\mathrm{ND}}\left(\mathrm{A} \beta\right.$ load) and $R_{1}$ (relative $\mathrm{CBF}$ ) gained from SRTM2 analyses of dynamic ${ }^{11} \mathrm{C}-\mathrm{PIB}$ stud-

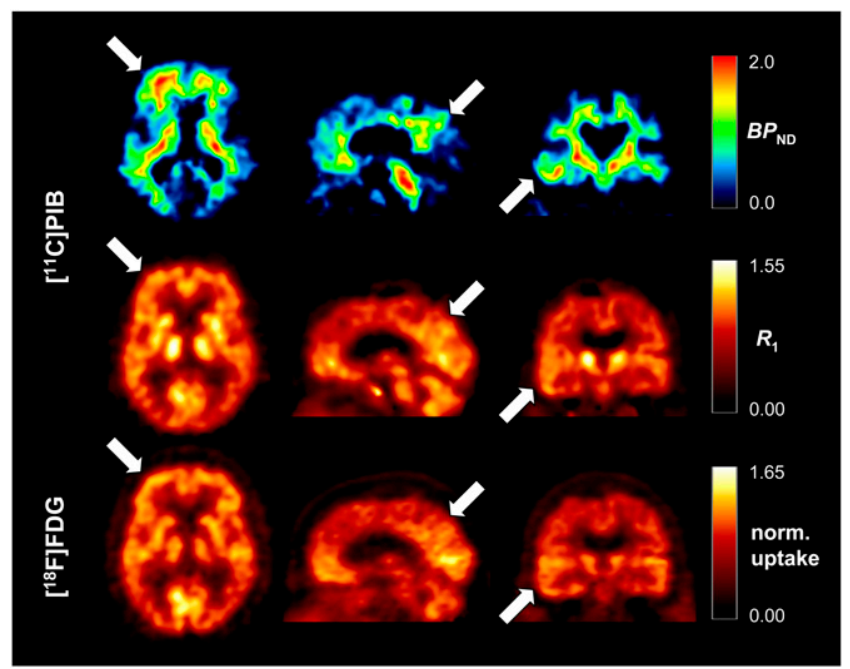

FIGURE 2. Parametric images of ${ }^{11} \mathrm{C}-\mathrm{PIB} B P_{\mathrm{ND}}$ (first row) and $R_{1}$ (second row) and normalized (norm.) ${ }^{18} \mathrm{~F}-\mathrm{FDG}$ uptake (third row) in patient with mild cognitive impairment (MMSE score, 28). Moderate $A \beta$ depositions are found in right frontal, temporoparietal, and posterior cingulate gyrus/precuneus cortex, with relatively preserved $R_{1}$ and normalized ${ }^{18} \mathrm{~F}$-FDG uptake in these areas (arrows). Note that cortical areas without significant $A \beta$ binding $\left(B P_{N D}, 0\right.$; e.g., left hemispheric cortex) appear as defects (color-coded in black), in contrast to strong nonspecific ${ }^{11} \mathrm{C}$-PIB binding in brain stem, thalamus, and white matter. (See legend to Fig. 1 for additional information.)

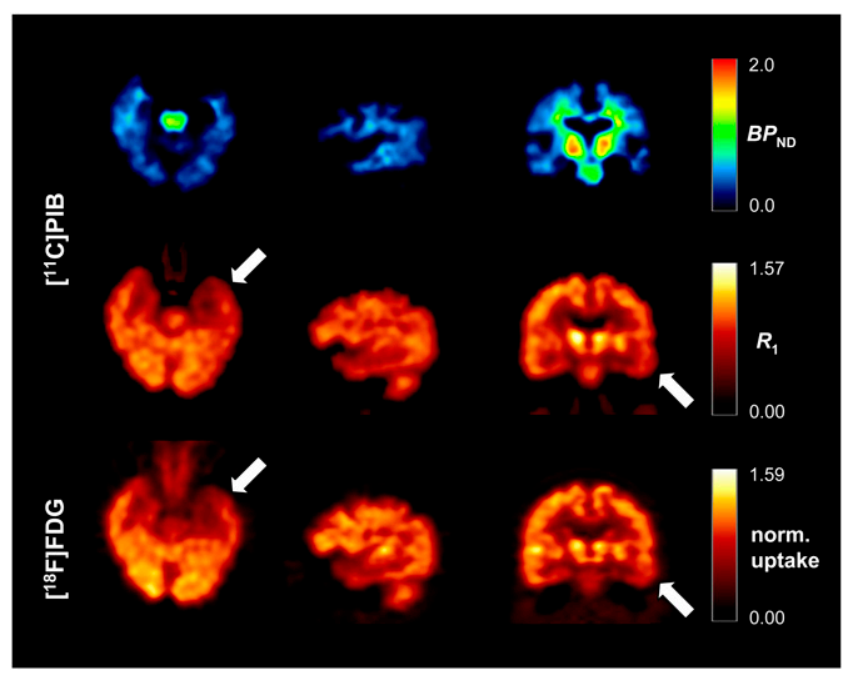

FIGURE 3. Parametric images of ${ }^{11} \mathrm{C}-\mathrm{PIB} B P_{\mathrm{ND}}$ (first row) and $R_{1}$ (second row) and normalized (norm.) ${ }^{18} \mathrm{~F}-\mathrm{FDG}$ uptake (third row) in patient with semantic dementia (MMSE score, 24). Whereas no relevant cortical $A \beta$ depositions are found, leftward asymmetric reduced $R_{1}$ and normalized ${ }^{18} \mathrm{~F}-\mathrm{FDG}$ uptake are detected in temporal lobes (arrows). Asymmetry of nonspecific ${ }^{11} \mathrm{C}-\mathrm{PIB}$ binding (first row) is primarily due to concomitant atrophy. (See legend to Fig. 1 for additional information.)

ies and ${ }^{18} \mathrm{~F}$-FDG uptake images normalized to cerebellar ${ }^{18} \mathrm{~F}-\mathrm{FDG}$ uptake. Images were acquired in 2 patients with probable AD (mild impairment shown in Fig. 1; severe impairment shown in Supplemental Fig. 1), 1 patient with MCI (Fig. 2), and 1 patient with semantic dementia (Fig. 3). The regional patterns of $R_{1}$ closely followed the regional patterns of ${ }^{18} \mathrm{~F}$-FDG uptake. Major abnormalities are clearly seen on ${ }^{18} \mathrm{~F}-\mathrm{FDG}$ and ${ }^{11} \mathrm{C}$-PIB $R_{1}$ images. However, on close inspection, differences are apparent in subcortical structures (thalamus and putamen), the pons/brain stem, and (less so) the mesiotemporal regions. In these regions, $R_{1}$ was relatively higher than ${ }^{18}$ F-FDG uptake. Nevertheless, this qualitative comparison strongly suggests that ${ }^{11} \mathrm{C}-\mathrm{PIB} R_{1}$ may serve as a marker of neuronal activity.

\section{Association Between ${ }^{11} \mathrm{C}$-PIB $\boldsymbol{R}_{1}$ and Normalized 18F-FDG Uptake}

The correlation between ${ }^{11} \mathrm{C}$-PIB $R_{1}$ and normalized regional ${ }^{18} \mathrm{~F}-\mathrm{FDG}$ uptake across all regions and subjects is shown in Figure 4. Normalized ${ }^{18}$ F-FDG uptake alone was highly predictive of ${ }^{11} \mathrm{C}$-PIB $R_{1}$, accounting for $62 \%$ of its variability $\left(R^{2}=0.62 ; F_{1,306}=502.6 ; P<0.00001\right.$; linear regression: ${ }^{11} \mathrm{C}-\mathrm{PIB} R_{1}=0.65 \times{ }^{18} \mathrm{~F}-\mathrm{FDG}$ uptake + 0.29). Categorizing regions into subcortical, limbic, and cortical regions (32) and adding region category to the model improved the overall model fit $\left(R^{2}=0.735 ; F_{3,306}=\right.$ 281.5; $P<0.00001)$. The results of regression analyses for these region categories (across subjects) are shown in Figure 4. There was a slight, albeit significant, interaction of region and ${ }^{18} \mathrm{~F}-\mathrm{FDG}$ uptake (affecting the regression slopes) (Fig. 4), which marginally improved the overall 


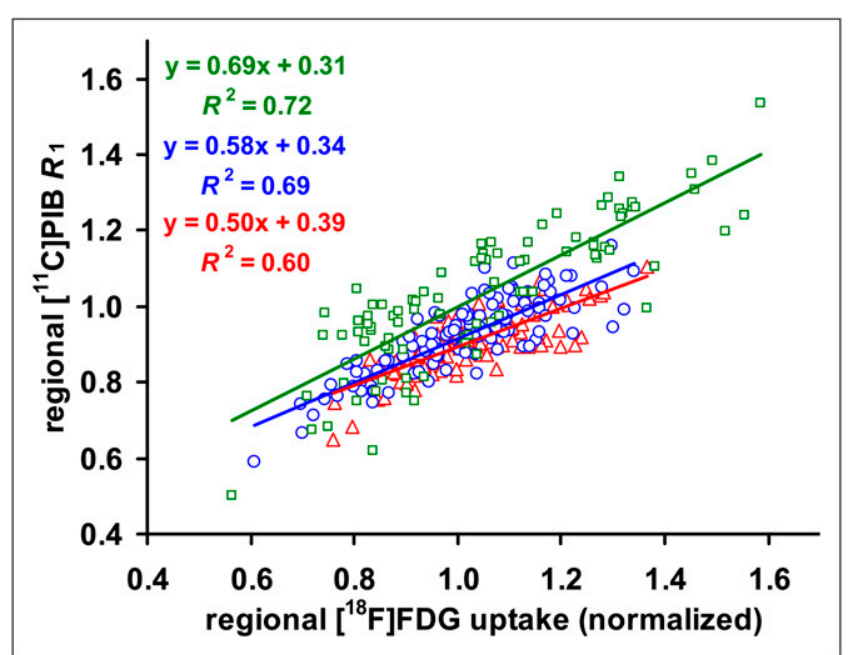

FIGURE 4. Association between relative regional CBF estimates gained from ${ }^{11} \mathrm{C}$-PIB PET $\left({ }^{11} \mathrm{C}\right.$-PIB $R_{1} ; y$-axis) and normalized regional ${ }^{18} \mathrm{~F}-\mathrm{FDG}$ uptake ( $x$-axis). Data are grouped in cortical (red), limbic (blue), and subcortical (green) regions. Results of linear regression analyses are given in corresponding colors in upper left corner.

model fit $\left(R^{2}=0.743 ; F_{5,302}=174.8 ; P<0.00001\right)$. Intraindividual regression analyses of PIB $R_{1}$ and normalized ${ }^{18} \mathrm{~F}$-FDG uptake (including all regions) indicated some interindividual variations in flow/metabolism coupling: The average regression slope and $y$-axis intercept were $0.76 \pm$ 0.14 and $0.17 \pm 0.12$, respectively $\left(R^{2}=0.73 \pm 0.11\right)$. Thus, subject identification was also entered into the regression model, leading to further improvement in the overall model fit $\left(R^{2}=0.83 ; F_{26,281}=53.27 ; P<\right.$ $0.00001)$. An interaction of subject identification and ${ }^{18} \mathrm{~F}-$ FDG uptake marginally improved the overall model fit $\left(R^{2}=0.86 ; F_{47,260}=33.15 ; P<0.00001\right)$. Thus, the final model accounted for $86 \%$ of ${ }^{11} \mathrm{C}$-PIB $R_{1}$ variability. It included normalized ${ }^{18} \mathrm{~F}-\mathrm{FDG}$ uptake as the most important predictor (effect test: $F_{1,260}=655.22 ; P<0.00001$ ) and region $\left(F_{2,260}=99.5 ; P<0.00001\right)$, subject identification $\left(F_{21,260}=6.9 ; P<0.00001\right)$, and the interactions of region and ${ }^{18}$ F-FDG uptake $\left(F_{2,260}=3.2 ; P=0.04\right)$ and subject identification and ${ }^{18} \mathrm{~F}$-FDG uptake $\left(F_{21,260}=2.2 ; P=\right.$ 0.002 ) as interacting categoric variables.

\section{SPM Analyses: MMSE Scores Versus Regional Measures of Neuronal Activity}

SPM analyses of correlations of ${ }^{11} \mathrm{C}-\mathrm{PIB} R_{1}$ and ${ }^{18} \mathrm{~F}-$ FDG uptake with MMSE scores were performed with a subgroup of 16 patients with early AD (14 with probable $\mathrm{AD}$ and two ${ }^{11} \mathrm{C}$-PIB-positive MCI patients) (Supplemental Fig. 2). Regarding positive correlations between ${ }^{18} \mathrm{~F}-\mathrm{FDG}$ uptake and MMSE scores, the largest correlation cluster covered the bilateral posterior cingulate gyrus/precuneus (maximum $t$ score $\left[t_{\max }\right] 5.87 ; k_{\mathrm{E}}, 2,015$ voxels; $P$ corrected at the cluster level $\left.\left[P_{\mathrm{c}-\mathrm{cl}}\right]=0.002\right)$. A similar positive correlation cluster in terms of statistical significance, size, and location was also found for the correlation between ${ }^{11} \mathrm{C}$ PIB $R_{1}$ and MMSE scores $\left(t_{\max }, 5.72 ; k_{\mathrm{E}}=1,980\right.$ voxels;
$\left.P_{\mathrm{c}-\mathrm{cl}}=0.001\right)$. Exceeding the findings for ${ }^{18} \mathrm{~F}-\mathrm{FDG},{ }^{11} \mathrm{C}-$ PIB $R_{1}$ also positively correlated with MMSE in bilateral clusters in the lateral inferior temporal cortex (left side: $t_{\max }, 3.95$, and $k_{\mathrm{E}}, 646$ voxels; right side: 2 clusters, $t_{\max }$, 3.88 , and sum $k_{\mathrm{E}}, 460$ voxels) and the temporoparietal junction (left side: $t_{\max }, 3.83$, and $k_{\mathrm{E}}, 232$ voxels; right side: 2 clusters, $t_{\max }, 5.37$, and sum $k_{\mathrm{E}}, 1,007$ voxels). Additional small positive correlation clusters were found in the bilateral cerebellum $\left({ }^{18} \mathrm{~F}-\mathrm{FDG}\right.$ and ${ }^{11} \mathrm{C}$-PIB $\left.R_{1}\right)$, left mesiotemporal lobe $\left({ }^{18} \mathrm{~F}-\mathrm{FDG}\right.$ only), pons, and left thalamus/internal capsule ( ${ }^{11} \mathrm{C}$-PIB $R_{1}$ only).

Concerning negative correlations between MMSE scores and ${ }^{18} \mathrm{~F}-\mathrm{FDG}$ uptake, the largest correlation cluster covered the bilateral apical sensorimotor cortex and extended into the bilateral paracentral lobule and anterior cingulate cortex $\left(t_{\max }, 5.87 ; k_{\mathrm{E}}, 2,420\right.$ voxels; $\left.P_{\mathrm{c}-\mathrm{cl}}=0.001\right)$. Additional negative correlation clusters were found in the right lateral sensorimotor cortex ( $t_{\max }, 5.90 ; k_{\mathrm{E}}, 674$ voxels), right anterior cingulate cortex ( $t_{\max }, 5.33 ; k_{\mathrm{E}}, 198$ voxels), and left striatum $\left(t_{\max }, 4.45 ; k_{\mathrm{E}}, 259\right.$ voxels). Regarding ${ }^{11} \mathrm{C}-\mathrm{PIB} R_{1}$, smaller clusters of negative correlations with MMSE scores were restricted to the left dorsolateral sensorimotor cortex $\left(t_{\max }\right.$, $6.12 ; k_{\mathrm{E}}, 251$ voxels) and right dorsolateral sensorimotor cortex ( 2 clusters: $t_{\max }, 5.46$; sum $k_{\mathrm{E}}, 481$ voxels), overlapping those detected for ${ }^{18} \mathrm{~F}-\mathrm{FDG}$ (Supplemental Fig. 2).

In contrast, there was no negative or positive correlation between $\mathrm{A} \beta$ load, as assessed with ${ }^{11} \mathrm{C}-\mathrm{PIB} B P_{\mathrm{ND}}$, and MMSE scores.

\section{DISCUSSION}

The results of the present study strongly suggest that relative regional CBF estimates $\left(R_{1}\right)$ derived from pharmacokinetic analysis of ${ }^{11} \mathrm{C}$-PIB PET studies represent a valid marker for synaptic dysfunction and neurodegeneration: Parametric $R_{1}$ images strongly resemble ${ }^{18}$ F-FDG uptake images, depicting congruent disease-specific patterns of CBF and glucose metabolism, respectively. Furthermore, regional $R_{1}$ and ${ }^{18} \mathrm{~F}$-FDG uptake values are closely correlated. Finally, $R_{1}$ and ${ }^{18}$ F-FDG uptake show very similar correlation patterns with severity of cognitive impairment as assessed by MMSE scores in early AD. Thus, a single ${ }^{11} \mathrm{C}$-PIB PET study may be used both for quantification of $\mathrm{A} \beta$-plaque load and for assessing functional consequences of neurodegeneration. The present approach circumvents the drawbacks associated with combined PET studies and, therefore, significantly facilitates dual biomarker imaging, as the patient needs to undergo only one PET study with considerably lower radiation exposure $(8.1 \mathrm{mSv}$ for combined ${ }^{11} \mathrm{C}$-PIB (500 MBq) and ${ }^{18} \mathrm{~F}-\mathrm{FDG}$ (300 MBq) PET studies compared with $2.4 \mathrm{mSv}$ for a single ${ }^{11} \mathrm{C}-\mathrm{PIB}$ study $\left.(33,34)\right)$.

For $B P_{\mathrm{ND}}$ and $R_{1}$ estimation, we used the SRTM2, which was previously validated as the reference tissue model most suitable for ${ }^{11} \mathrm{C}$-PIB analyses (25). Earlier studies indicated that 2 tissue compartments are needed for accurate description of ${ }^{11} \mathrm{C}$-PIB tissue kinetics (22). Although this violates 
the underlying assumption of a single tissue compartment in the target and the reference region made by SRTM, the resulting $B P_{\mathrm{ND}}$ bias is small (on average, $6 \%$ and $-3 \%$ in ${ }^{11} \mathrm{C}$-PIB-negative and ${ }^{11} \mathrm{C}$-PIB-positive patients) (23). Furthermore, adding a second tissue compartment to the target or reference region model does not improve model fits or $B P_{\mathrm{ND}}$ estimates (24). Taken together, this strongly suggests that the SRTM2 yields valid estimates of $B P_{\mathrm{ND}}$ and $R_{1}$. Mean $k_{2}{ }^{\prime}$ values estimated in our study are in good agreement with $k_{2}{ }^{\prime}$ estimates reported by Zhou et al. (31) (on average 0.04 to $0.06 \mathrm{~min}^{-1}$ in both studies). Because $R_{1}$ is insensitive to minor inaccuracies in $k_{2}{ }^{\prime}(31)$ and because relatively long scan durations are primarily needed to gain precise estimates of $B P_{\mathrm{ND}}$ and $k_{2}{ }^{\prime}$, we investigated how $R_{1}$ is affected if $k_{2}{ }^{\prime}$ is simply fixed to $0.05 \mathrm{~min}^{-1}$ and scan duration is reduced to only $20 \mathrm{~min}$ (not shown in detail): This resulted in only marginally higher $(1 \% \pm 1 \% ; P<$ $0.00001)$ and still highly correlated $\left(R^{2}=0.99\right) R_{1}$ estimates, again underlining the robustness of $R_{1}$. In addition, we explored regional ${ }^{11} \mathrm{C}$-PIB uptake during the first $6 \mathrm{~min}$ (as used for initial spatial normalization, see "Materials and Methods") as an index of CBF: calculated values of initial regional ${ }^{11} \mathrm{C}$-PIB uptake normalized by cerebellar uptake were only moderately higher than 60-min $R_{1}$ estimates (5\% $\pm 3 \% ; P<0.00001)$, the correlation between both measures being still very high $\left(R^{2}=0.95\right)$. Thus, a brief preceding PET session for generation of relative $\mathrm{CBF}$ maps may be simply added to the late-scan ${ }^{11} \mathrm{C}$-PIB PET (e.g., 40-60 or 50-70 min to calculate standardized uptake value ratios) $(23,25)$ used in many institutions at the moment. However, it has to be emphasized that only full dynamic data acquisition with subsequent pharmacokinetic analyses (as done in the present work) allows for an estimation of $\mathrm{A} \beta$ load $\left(B P_{\mathrm{ND}}\right)$ that is least biased by nonspecific effects like $\mathrm{CBF}$ changes and peripheral tracer clearance. This is of particular importance for follow-up studies and treatment trials. In our experience, a 1-h scan duration is well tolerated by virtually all patients with MCI or mild to moderate dementia.

${ }^{11} \mathrm{C}$-PIB $R_{1}$ estimates are highly correlated to normalized regional ${ }^{18} \mathrm{~F}$-FDG uptake values. This would be expected if ${ }^{11} \mathrm{C}$-PIB $R_{1}$ is a valid marker of CBF based on tight flow/ metabolism coupling (2). Across all subjects and regions, ${ }^{18}$ F-FDG uptake predicted about $62 \%$ of ${ }^{11} \mathrm{C}$-PIB $R_{1}$ variability. However, this relationship was not homogeneous across regions, with relatively higher ${ }^{11} \mathrm{C}$-PIB $R_{1}$ values in thalamus, striatum, pons, and mesiotemporal lobe (Figs. 1-3). This observation agrees with a recent study by Gur et al. (32), who, by comparing ${ }^{15} \mathrm{O}$-water and ${ }^{18} \mathrm{~F}$-FDG PET studies of healthy controls, demonstrated a relative hyperperfusion of subcortical and limbic structures, whereas association cortices are relatively hypoperfused. They speculated that this may represent an anticipatory flow/ metabolism uncoupling in regions that share the need for a rapid response to external stimuli and arousal, in contrast to association cortices that are involved in more down- stream processing (32). Consequently, after this region grouping was included in the regression model, it improved to account for $74 \%$ of ${ }^{11} \mathrm{C}$-PIB $R_{1}$ variability. Furthermore, there was some interindividual variability of regression slopes (coefficient of variation, $18 \%$ ) between ${ }^{11} \mathrm{C}-\mathrm{PIB} R_{1}$ and normalized ${ }^{18} \mathrm{~F}-\mathrm{FDG}$ uptake (including all regions). This is not unexpected, given that various, hardly controllable individual systemic and local cerebral factors possibly affected flow/metabolism coupling $(2,35)$. Thus, entering subject identification into the regression model also improved overall model fit, finally accounting for about $86 \%$ of ${ }^{11} \mathrm{C}$-PIB $R_{1}$ variability.

Of note, the regression slopes between ${ }^{11} \mathrm{C}-\mathrm{PIB} R_{1}$ and normalized ${ }^{18} \mathrm{~F}$-FDG uptake were less than 1 (on average $0.76 \pm 0.14$ within subjects; see also Fig. 4 ), which suggest that ${ }^{11} \mathrm{C}$-PIB $R_{1}$ possesses a restricted dynamic range and, thus, lower diagnostic sensitivity compared with ${ }^{18} \mathrm{~F}-\mathrm{FDG}$. A limited diagnostic sensitivity was indeed observed for the diagnosis of AD with ${ }^{15} \mathrm{O}$-water PET (36). Furthermore, in direct comparison to ${ }^{18} \mathrm{~F}$-FDG PET, the sensitivity of ${ }^{123} \mathrm{I}-$ IMP SPECT was somewhat lower (70\% vs. $86 \%$ ), albeit overall diagnostic accuracy in moderate $\mathrm{AD}$ did not differ (3). This underlines the need for further prospective studies to validate the diagnostic value of dual-biomarker ${ }^{11} \mathrm{C}$-PIB PET studies in comparison to combined ${ }^{18} \mathrm{~F}$-FDG and ${ }^{11} \mathrm{C}$ PIB PET studies for diagnosis and monitoring of the progression of $\mathrm{AD}$.

Flow/metabolism coupling may be altered by several mechanisms in $\mathrm{AD}$, including disruption/alteration of the vasodilatory cholinergic nucleus basalis of Meynert, alterations of glycolytic enzymes and glucose transporters, and amyloid angiopathy (35). However, a recent study with a combination of encephalography and Doppler sonography showed preserved activation/flow coupling on visual stimulation in AD (37), and coupled changes of glucose metabolism and $\mathrm{CBF}$ were observed in the aforementioned combined ${ }^{18}$ F-FDG PET and ${ }^{123}$ I-IMP SPECT studies (3). Nevertheless, future studies with sufficient statistical power need to exclude possible systematic effects of AD pathology on the validity of the proposed method, for example, by comparing ${ }^{11} \mathrm{C}$-PIB $R_{1}$ /glucose metabolism coupling in well-defined AD and non-AD populations. As a preliminary impression, we did not observe an obvious effect of ${ }^{11} \mathrm{C}$ PIB positivity on ${ }^{11} \mathrm{C}$-PIB $R_{1}$ /glucose metabolism coupling.

Finally, we used SPM analyses to assess the correlation between severity of cognitive symptoms (MMSE scores) and PET measures. Regarding positive correlations, most relevant and well-agreeing (in terms of location, size, and $t$ score) correlation clusters covered the bilateral posterior cingulate gyrus/precuneus for both ${ }^{11} \mathrm{C}$-PIB $R_{1}$ and ${ }^{18} \mathrm{~F}-$ FDG (Supplemental Fig. 2). This perfectly agrees with previous studies indicating that earliest $A D$-related metabolic changes occur in this region (17). Also in line with earlier studies $(16,17)$, additional smaller positive correlation clusters were located in the bilateral temporoparietal cortex for ${ }^{11}$ C-PIB $R_{1}$. For ${ }^{18}$ F-FDG, a comparable left temporopar- 
ietal cluster occurred at a slightly lowered statistical threshold $(P<0.01)$. In turn, Nihashi et al. (3) observed highly correlated changes of CBF and glucose metabolism in temporoparietal cortex $(r=0.82)$, whereas the correlation of changes in posterior cingulate gyrus/precuneus was moderate $(r=0.63)$. This difference may be explained by the fact that Nihashi et al. (3) included patients with moderate AD, whereas we contemplated patients with mild $\mathrm{AD}$ and ${ }^{11} \mathrm{C}$ PIB-positive MCI. Furthermore, Nihashi et al. (3) used CBF SPECT, which may be disadvantageous in posterior cingulate gyrus/precuneus because of its lower resolution and sensitivity. These findings illustrate that, despite a possibly limited dynamic range, ${ }^{11} \mathrm{C}-\mathrm{PIB} R_{1}$ should be a sensitive marker of disease severity and progression in early AD. Clearly unexpected ${ }^{11} \mathrm{C}$-PIB $R_{1}$ correlation clusters occurred in pons and the left thalamus/internal capsule. They may result from the liberal statistical threshold used (false positives) but may also represent artifacts related to the high nonspecific ${ }^{11} \mathrm{C}$-PIB uptake in these regions. Concerning negative correlations with MMSE scores (i.e., relatively spared areas given that proportional scaling was performed), prominent overlapping correlation clusters were found in bilateral sensorimotor cortex for both methods, although being larger for ${ }^{18} \mathrm{~F}-\mathrm{FDG}$ than for ${ }^{11} \mathrm{C}$-PIB $R_{1}$, in line with an earlier ${ }^{18}$ F-FDG PET study (23). Lowering the statistical threshold to $P<0.01$ had relatively little effect on these ${ }^{11} \mathrm{C}$-PIB $R_{1}$ correlation clusters, which may signify CBF-limited ${ }^{11} \mathrm{C}$-PIB extraction in these highflow areas. In contrast to ${ }^{18} \mathrm{~F}-\mathrm{FDG}$ uptake and $R_{1}$ maps, no significant correlation could be detected between MMSE scores and ${ }^{11} \mathrm{C}-\mathrm{PIB} B P_{\mathrm{ND}}$. This agrees with previous combined ${ }^{18} \mathrm{~F}$-FDG and ${ }^{11} \mathrm{C}$-PIB studies in $\mathrm{AD}$ that found (positive) correlations of cognitive scores with ${ }^{18} \mathrm{~F}$-FDG uptake but no or only considerably weaker (negative) correlations with $A \beta$ load (or changes thereof) $(7,13,14,18)$.

\section{CONCLUSION}

Voxelwise pharmacokinetic analyses of dynamic ${ }^{11} \mathrm{C}$ PIB studies provide high-quality $R_{1}$ images of relative regional $\mathrm{CBF}$ that are well comparable to ${ }^{18} \mathrm{~F}$-FDG PET images. The high correlation between ${ }^{11} \mathrm{C}-\mathrm{PIB} R_{1}$ and ${ }^{18} \mathrm{~F}-\mathrm{FDG}$ uptake and the good agreement of both methods in terms of correlation with symptom severity (MMSE scores) strongly suggest that ${ }^{11} \mathrm{C}-\mathrm{PIB} R_{1}$ can serve as a complementary biomarker of neuronal activity and, thus, neurodegeneration in addition to $\mathrm{A} \beta$ load given by ${ }^{11} \mathrm{C}$ PIB $B P_{\mathrm{ND}}$.

\section{REFERENCES}

1. Nordberg A, Rinne JO, Kadir A, Långström B. The use of PET in Alzheimer disease. Nat Rev Neurol. 2010;6:78-87.

2. Paulson OB, Hasselbalch SG, Rostrup E, Knudsen GM, Pelligrino D. Cerebral blood flow response to functional activation. J Cereb Blood Flow Metab. 2010;30:2-14.

3. Nihashi T, Yatsuya H, Hayasaka K, et al. Direct comparison study between FDGPET and IMP-SPECT for diagnosing Alzheimer's disease using 3D-SSP analysis in the same patients. Radiat Med. 2007;25:255-262.
4. Klunk WE, Engler H, Nordberg A, et al. Imaging brain amyloid in Alzheimer's disease with Pittsburgh Compound-B. Ann Neurol. 2004;55:306-319.

5. Jack CR Jr, Knopman DS, Jagust WJ, et al. Hypothetical model of dynamic biomarkers of the Alzheimer's pathological cascade. Lancet Neurol. 2010;9:119-128.

6. Rowe CC, Ng S, Ackermann U, et al. Imaging beta-amyloid burden in aging and dementia. Neurology. 2007;68:1718-1725.

7. Edison P, Archer HA, Hinz R, et al. Amyloid, hypometabolism, and cognition in Alzheimer disease: an $\left[{ }^{11} \mathrm{C}\right] \mathrm{PIB}$ and $\left[{ }^{18} \mathrm{~F}\right] \mathrm{FDG}$ PET study. Neurology. 2007;68: 501-518.

8. Gomperts SN, Rentz DM, Moran E, et al. Imaging amyloid deposition in Lewy body diseases. Neurology. 2008;71:903-910.

9. Morris JC, Roe CM, Xiong C, et al. APOE predicts amyloid-beta but not tau Alzheimer pathology in cognitively normal aging. Ann Neurol. 2010;67:122-131.

10. Pike KE, Savage G, Villemagne VL, et al. Beta-amyloid imaging and memory in non-demented individuals: evidence for preclinical Alzheimer's disease. Brain. 2007;130:2837-2844.

11. Morris JC, Roe CM, Grant EA, et al. Pittsburgh compound B imaging and prediction of progression from cognitive normality to symptomatic Alzheimer disease. Arch Neurol. 2009;66:1469-1475.

12. Forsberg A, Engler H, Almkvist O, et al. PET imaging of amyloid deposition in patients with mild cognitive impairment. Neurobiol Aging. 2008;29:1456-1465.

13. Engler H, Forsberg A, Almkvist O, et al. Two-year follow-up of amyloid deposition in patients with Alzheimer's disease. Brain. 2006;129:2856-2866.

14. Kadir A, Almkvist O, Forsberg A, et al. Dynamic changes in PET amyloid and FDG imaging at different stages of Alzheimer's disease. Neurobiol Aging. August 3, 2010 [Epub ahead of print].

15. Rinne JO, Brooks DJ, Rossor MN, et al. ${ }^{11} \mathrm{C}-\mathrm{PiB}$ PET assessment of change in fibrillar amyloid-beta load in patients with Alzheimer's disease treated with bapineuzumab: a phase 2, double-blind, placebo-controlled, ascending-dose study. Lancet Neurol. 2010;9:363-372.

16. Herholz K, Salmon E, Perani D, et al. Discrimination between Alzheimer dementia and controls by automated analysis of multicenter FDG PET. Neuroimage. 2002;17:302-316.

17. Minoshima S, Giordani B, Berent S, Frey KA, Foster NL, Kuhl DE. Metabolic reduction in the posterior cingulate cortex in very early Alzheimer's disease. Ann Neurol. 1997;42:85-94.

18. Kadir A, Andreasen N, Almkvist O, et al. Effect of phenserine treatment on brain functional activity and amyloid in Alzheimer's disease. Ann Neurol. 2008;63: 621-631.

19. Koeppe RA, Gilman S, Joshi A, et al. ${ }^{11} \mathrm{C}-\mathrm{DTBZ}$ and ${ }^{18} \mathrm{~F}-\mathrm{FDG}$ PET measures in differentiating dementias. J Nucl Med. 2005;46:936-944.

20. Van Laere K, Clerinx K, D'Hondt E, de Groot T, Vandenberghe W. Combined striatal binding and cerebral influx analysis of dynamic ${ }^{11} \mathrm{C}$-raclopride PET improves early differentiation between multiple-system atrophy and Parkinson disease. J Nucl Med. 2010;51:588-595.

21. Blomquist G, Engler H, Nordberg A, et al. Unidirectional influx and net accumulation of PIB. Open Neuroimag J. 2008;2:114-125.

22. Price JC, Klunk WE, Lopresti BJ, et al. Kinetic modeling of amyloid binding in humans using PET imaging and Pittsburgh Compound-B. J Cereb Blood Flow Metab. 2005;25:1528-1547.

23. Lopresti BJ, Klunk WE, Mathis CA, et al. Simplified quantification of Pittsburgh compound B amyloid imaging PET studies: a comparative analysis. J Nucl Med. 2005;46:1959-1972.

24. Zhou Y, Resnick SM, Ye W, et al. Using a reference tissue model with spatial constraint to quantify $\left[{ }^{11} \mathrm{C}\right]$ Pittsburgh compound B PET for early diagnosis of Alzheimer's disease. Neuroimage. 2007;36:298-312.

25. Yaqub M, Tolboom N, Boellaard R, et al. Simplified parametric methods for $\left[{ }^{11} \mathrm{C}\right] \mathrm{PIB}$ studies. Neuroimage. 2008;42:76-86.

26. Wu Y, Carson RE. Noise reduction in the simplified reference tissue model for neuroreceptor functional imaging. J Cereb Blood Flow Metab. 2002;22:1440-1452.

27. McKhann G, Drachman D, Folstein M, Katzman R, Price D, Stadlan EM. Clinical diagnosis of Alzheimer's disease: report of the NINCDS-ADRDA Work Group under the auspices of Department of Health and Human Services Task Force on Alzheimer's Disease. Neurology. 1984;34:939-944.

28. Neary D, Snowden JS, Gustafson L, et al. Frontotemporal lobar degeneration: a consensus on clinical diagnostic criteria. Neurology. 1998;51:1546-1554.

29. Petersen RC. Mild cognitive impairment as a diagnostic entity. J Intern Med. 2004;256:183-194.

30. Solbach C, Uebele M, Reischl G, Machulla HJ. Efficient radiosynthesis of carbon-11 labelled uncharged Thioflavin $\mathrm{T}$ derivatives using $\left[{ }^{11} \mathrm{C}\right]$ methyl triflate for beta-amyloid imaging in Alzheimer's disease with PET. Appl Radiat Isot. 2005;62:591-595.

31. Lammertsma AA, Hume SP. Simplified reference tissue model for PET receptor studies. Neuroimage. 1996;4:153-158. 
32. Gur RC, Ragland JD, Reivich M, Greenberg JH, Alavi A, Gur RE. Regional differences in the coupling between resting cerebral blood flow and metabolism may indicate action preparedness as a default state. Cereb Cortex. 2009;19: 375-382.

33. Scheinin NM, Tolvanen TK, Wilson IA, Arponen EM, Någren KA, Rinne JO. Biodistribution and radiation dosimetry of the amyloid imaging agent ${ }^{11} \mathrm{C}-\mathrm{PIB}$ in humans. J Nucl Med. 2007;48:128-133.

34. Varrone A, Asenbaum S, Vander Borght T, et al. EANM procedure guidelines for PET brain imaging using $\left[{ }^{18} \mathrm{~F}\right] \mathrm{FDG}$, version 2. Eur J Nucl Med Mol Imaging. 2009;36:2103-2110.
35. Gsell W, De Sadeleer C, Marchalant Y, MacKenzie ET, Schumann P, Dauphin F. The use of cerebral blood flow as an index of neuronal activity in functional neuroimaging: experimental and pathophysiological considerations. J Chem Neuroanat. 2000;20:215-224

36. Powers WJ, Perlmutter JS, Videen TO, et al. Blinded clinical evaluation of positron emission tomography for diagnosis of probable Alzheimer's disease. Neurology. 1992;42:765-770.

37. Rosengarten B, Paulsen S, Molnar S, Kaschel R, Gallhofer B, Kaps M. Activationflow coupling differentiates between vascular and Alzheimer type of dementia. J Neurol Sci. 2007;257:149-154. 